\title{
RELIABILITY, AVAILABILITY AND COST ANALYSIS OF LARGE MULTI-STATE SYSTEMS WITH AGEING COMPONENTS
}

\author{
ANALIZA NIEZAWODNOŚĆI, GOTOWOŚCI \\ I KOSZTÓW DUŻYCH SYSTEMÓW \\ WIELOSTANOWYCH ZE STARZEJĄCYMI SIĘ \\ ELEMENTAMI
}

\author{
Krzysztof Kołowrocki, Joanna Soszyńska
}

Gdynia Maritime University

Akademia Morska w Gdyni

81-225 Gdynia, ul. Morska 81-87

e-mails: katmatkk@am.gdynia.pl, joannas@am.gdynia.pl

\begin{abstract}
Basic notions of the system multi-state reliability analysis are introduced. The multi-state series system with degrading components is defined and its exact reliability function is determined. The limit reliability function for large multi-state systems is introduced. An auxiliary theorem on limit reliability function of a large multi-state series system, which is necessary for its approximate reliability evaluation, is presented. On the basis of this auxiliary theorem some corollaries are formulated and proved and then applied to approximate reliability and availability determination of a large multi-state series system. Evaluations are given of a multi-state system reliability function, its mean lifetimes in the state subsets and their standard deviations, mean value and variance of the lifetime up to and the number of exceeding the system reliability critical state and its availability coefficient. The cost analysis of a multi-state series system is performed as well. The results are applied to a large telecommunication network reliability, availability and cost analysis.
\end{abstract}

Keywords: system, reliability, availability

Streszczenie: Wprowadzono podstwowe pojęcia dotyczące analizy niezawodności systemów wielostanowych. Zdefiniowano wielostanowy system szeregowy ze starzejącymi się elementami oraz wyznaczono jego dokładną funkcję niezawodnośći. Przedstawiono twierdzenie, dotyczace granicznej funkcji niezawodności systemu szeregowego, niezbedne do przybliżonego oszacowania jego niezawodności. Na podstawie tego twierdzenia sformułowano i udowodniono wnioski, ktore zastosowano do oszacowania niezawodności i gotowości dużego wielostanowego systemu szeregowego. Dla tego systemu wielostanowego oszacowano funkcję niezawodności, średnie czasy przebywania $\mathrm{w}$ podzbiorach stanów niezawodnościowych, odchylenie standardowe, wartość średnią i wariancję czasu przebywania powyżej niezawodnościowego stanu krytycznego systemu, a także jego współczynnik gotowości. Przeprowadzono rownież analizę kosztów tego systemu. Otrzymane rezultaty zastosowano do analizy niezawodności, gotowości i kosztów dużej sieci telekomunikacyjnej.

Słowa kluczowe: system, niezawodność, gotowość 


\section{RELIABILITY, AVAILABILITY AND COST ANALYSIS OF LARGE MULTI-STATE SYSTEMS WITH AGEING COMPONENTS}

\section{Introduction}

Many technical systems belong to the class of complex systems as a result of the large number of components they are built of and their complicated operating processes. Taking into account the importance of the safety and operating process effectiveness of such systems it seems reasonable to expand the two-state approach to multi-state approach in their reliability analysis considered for instance in [1]-[5]. These more general and practically important complex systems composed of multi-state and degrading in time components are considered among others in [2] and [5]. An especially important role they play in the evaluation of large scale technical systems reliability and safety is defined in [3]. The assumption that the systems are composed of multi-state components with reliability states degrading in time without repair gives the possibility for more precise analysis of their reliability, safety and operational processes' effectiveness. This assumption allows us to distinguish a system reliability critical state to exceed which is either dangerous for the environment or does not assure the necessary level of its operational process effectiveness. Then, an important system reliability characteristic is the time to the moment of exceeding the system reliability critical state and its distribution. This distribution is strictly related to the system multi-state reliability function that is a basic characteristic of the multi-state system. In the case of large systems, the determination of the exact reliability functions of the systems and the system risk functions leads us to very complicated formulae that are often useless for reliability practitioners. One of the important techniques in this situation is the asymptotic approach [3] to system reliability evaluation. In this approach, instead of the preliminary complex formula for the system reliability function, after assuming that the number of system components tends to infinity and finding the limit reliability of the system, we obtain its simplified form. In the paper, there are some applications of the presented theoretical results on large multi-state series systems applying to the evaluation of reliability and availability characteristics and cost analysis of a large telecommunication network. 


\section{Multi-state systems with ageing components}

In the multi-state reliability analysis to define systems with degrading (ageing) components we assume that:

$-E_{i}, i=1,2, \ldots, n$, are components of a system,

-all components and a system under consideration have the state set $\{0,1, \ldots, z\}, z \geq 1$,

-the state indexes are ordered, the state 0 is the worst and the state $z$ is the best,

$-T_{i}(u), i=1,2, \ldots, n$, are independent random variables representing the lifetimes of components $E_{i}$ in the state subset $\{u, u+1, \ldots, z\}$, while they were in the state $z$ at the moment $t=0$,

$-T(u)$ is a random variable representing the lifetime of a system in the state subset $\{u, u+1, \ldots, z\}$ while it was in the state $z$ at the moment $t=0$,

-the system state degrades with time $t$ without repair,

$-e_{i}(t)$ is a component $E_{i}$ state at the moment $\left.t, t \in<0, \infty\right)$, given that it was in the state $z$ at the moment $t=0$,

$-s(t)$ is a system state at the moment $t, t \in<0, \infty)$, given that it was in the state $z$ at the moment $t=0$.

The above assumptions mean that the states of the system with degrading components may be changed in time only from better to worse. The way in which the components and the system states change is illustrated in (Fig. 1).

\section{transitions}

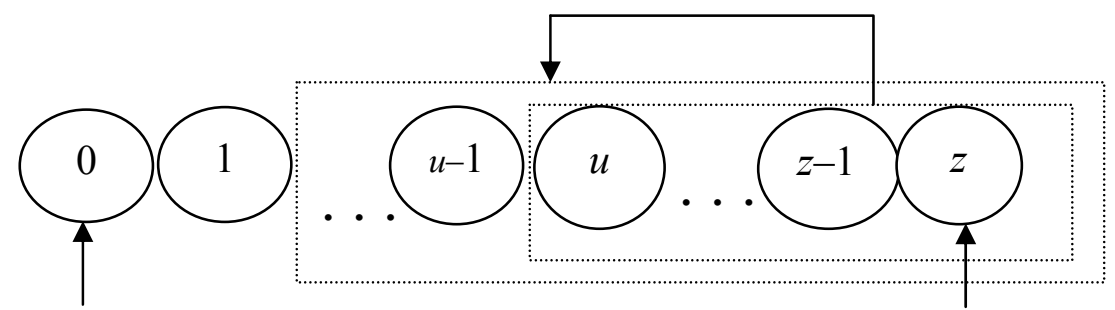

worst state

best state

Fig. 1. Illustration of states changing in system with ageing components

Definition 1. A vector

$\left.R_{i}(t, \cdot)=\left[R_{i}(t, 0), R_{i}(t, 1), \ldots, R_{i}(t, z)\right], t \in<0, \infty\right), i=1,2, \ldots, n$, 
where

$\left.R_{i}(t, u)=P\left(e_{i}(t) \geq u \mid e_{i}(0)=z\right)=P\left(T_{i}(u)>t\right), t \in<0, \infty\right), u=0,1, \ldots, z$,

is the probability that the component $E_{i}$ is in the state subset $\{u, u+1, \ldots, z\}$ at the moment $t, t \in<0, \infty)$, while it was in the state $z$ at the moment $t=0$, is called the multi-state reliability function of a component $E_{i}$.

Definition 2. A vector

$\left.\boldsymbol{R}_{n}(t, \cdot)=\left[1, \boldsymbol{R}_{n}(t, 1), \ldots, \boldsymbol{R}_{n}(t, z)\right], t \in<0, \infty\right)$,

where

$\left.\boldsymbol{R}_{n}(t, u)=P(s(t) \geq u \mid s(0)=z)=P(T(u)>t), t \in<0, \infty\right), u=0,1, \ldots, z$,

is the probability that the system is in the state subset $\{u, u+1, \ldots, z\}$ at the moment $t, t \in<0, \infty)$, while it was in the state $z$ at the moment $t=0$, is called the multi-state reliability function of a system.

Definition 3. A multi-state system is called series if its lifetime $T(u)$ in the state subset $\{u, u+1, \ldots, z\}$ is given by

$T(u)=\min _{1 \leq i \leq n}\left\{T_{i}(u)\right\}, u=1,2, \ldots, z$.

The above definition means that a multi-state series system is in the state subset $\{u, u+1, \ldots, z\}$ if and only if all its components are in this subset of states.

It is easy to work out that the reliability function of the multi-state series system is given by

$$
\left.\boldsymbol{R}_{n}(t, \cdot)=\left[1, \boldsymbol{R}_{n}(t, 1), \ldots, \boldsymbol{R}_{n}(t, z)\right], t \in<0, \infty\right),
$$

where

$$
\left.\boldsymbol{R}_{n}(t, u)=\prod_{i=1}^{n} R_{i}(t, u), t \in<0, \infty\right), u=1,2, \ldots, z .
$$


Definition 4. A multi-state series system is called homogeneous if its component lifetimes $T_{i}(u)$ in the state subsets have an identical distribution function

$F_{i}(t, u)=F(t, u), u=1,2, \ldots, z, t \in(-\infty, \infty), i=1,2, \ldots, n$,

i.e. if its components $E_{i}$ have the same reliability function

$R_{i}(t, u)=R(t, u)=1-F(t, u), u=1,2, \ldots, z, t \in(-\infty, \infty), i=1,2, \ldots, n$.

The reliability function of the homogeneous multi-state series system is given by

$\left.\boldsymbol{R}_{n}(t, \cdot)=\left[1, \boldsymbol{R}_{n}(t, 1), \ldots, \boldsymbol{R}_{n}(t, z)\right], t \in<0, \infty\right)$,

where

$\left.\boldsymbol{R}_{n}(t, u)=[R(t, u)]^{n}, t \in<0, \infty\right), u=1,2, \ldots, z$.

\section{Reliability of large multi-state systems}

In the asymptotic approach to multi-state system reliability analysis we are interested in the limit distributions of a standardised random variable

$$
\left(T(u)-b_{n}(u)\right) / a_{n}(u), u=1,2, \ldots, z,
$$

where $T(u)$ is the lifetime of the system in the state subset $\{u, u+1, \ldots, z\}$ and

$a_{n}(u)>0, b_{n}(u) \in(-\infty, \infty), u=1,2, \ldots, z$,

are some suitably chosen numbers, called normalising constants. And, since

$$
\begin{aligned}
P\left(\left(T(u)-b_{n}(u)\right) / a_{n}(u)>t\right) & =P\left(T(u)>a_{n}(u) t+b_{n}(u)\right) \\
& =\boldsymbol{R}_{n}\left(a_{n}(u) t+b_{n}(u), u\right), u=1,2, \ldots, z,
\end{aligned}
$$

where 


$$
\boldsymbol{R}_{n}(t, \cdot)=\left[\boldsymbol{R}_{n}(t, 0), \boldsymbol{R}_{n}(t, 1), \ldots, \boldsymbol{R}_{n}(t, z)\right], t \in(-\infty, \infty),
$$

is the multi-state reliability function of the system composed of $n$ components, then we assume the following definition.

Definition 5. A vector

$\mathfrak{R}(t, \cdot)=[1, \mathfrak{R}(t, 1), \ldots, \mathfrak{R}(t, z)], t \in(-\infty, \infty)$,

is called the limit multi-state reliability function of the system with reliability function $\boldsymbol{R}_{n}(t, \cdot)$ if there exist normalising constants $a_{n}(u)>0$, $b_{n}(u) \in(-\infty, \infty)$, such that

$\lim _{n \rightarrow \infty} \boldsymbol{R}_{n}\left(a_{n}(u) t+b_{n}(u), u\right)=\mathfrak{R}(t, u)$ for $t \in C_{\mathfrak{R}(u)}, u=1,2, \ldots, z$

where $C_{\mathfrak{R}(u)}$ is the set of continuity points of $\mathfrak{R}(t, u)$.

Knowing the system limit reliability function allows us, for sufficiently large $n$, to apply the following approximate formula

$\boldsymbol{R}_{n}(t, \cdot) \cong \mathfrak{R}\left(\frac{t-b_{n}(u)}{a_{n}(u)}, \cdot\right)$,

i.e.

$\left[1, \boldsymbol{R}_{n}(t, 1), \ldots, \boldsymbol{R}_{n}(t, z)\right] \cong\left[1, \mathfrak{R}\left(\frac{t-b_{n}(1)}{a_{n}(1)}, 1\right), \ldots, \mathfrak{R}\left(\frac{t-b_{n}(z)}{a_{n}(z)}, z\right)\right], t \in(-\infty, \infty)$.

In proving facts on limit reliability functions of homogeneous multi-state series systems we can apply either directly Definition 5 or the following lemma [3].

Lemma 1. If

(i) $\mathfrak{R}(t, u)=\exp [-V(t, u)], u=1,2, \ldots, z$, is a non-degenerate reliability function,

(ii) $\boldsymbol{R}_{n}(t, \cdot)=\left[1, \boldsymbol{R}_{n}(t, 1), \ldots, \boldsymbol{R}_{n}(t, z)\right], t \in(-\infty, \infty)$, is the reliability function of a homogeneous multi-state series system defined by (1)-(2), 
(iii) $a_{n}(u)>0, b_{n}(u) \in(-\infty, \infty), u=1,2, \ldots, z$,

then

$\mathfrak{R}(t, \cdot)=[1, \mathfrak{R}(t, 1), \ldots, \mathfrak{R}(t, z)], t \in(-\infty, \infty)$,

is the multi-state limit reliability function of this system, i.e.

$\lim _{n \rightarrow \infty} \boldsymbol{R}_{n}\left(a_{n}(u) t+b_{n}(u), u\right)=\mathfrak{R}(t, u)$ for $t \in C_{\mathfrak{R}(u)}, u=1,2, \ldots, z$,

if and only if

$\lim _{n \rightarrow \infty} n F\left(a_{n}(u) t+b_{n}(u), u\right)=V(t, u)$ for $t \in C_{V(u)}, u=1,2, \ldots, z$.

Direct application of Definition 5 or Lemma 1 results in the following corollary.

Corollary 1. If the homogeneous multi-state series system is composed of components having exponential reliability functions

$R(t, \cdot)=[1, R(t, 1), \ldots, R(t, z)], t \in(-\infty, \infty)$,

where

$R(t, u)=1$ for $t<0, R(t, u)=\exp [-\lambda(u) t]$ for $t \geq 0, \lambda(u)>0, u=1,2, \ldots, z$,

and

$a_{n}(u)=\frac{1}{n \lambda(u)}, b_{n}(u)=0, \quad u=1,2, \ldots, z$,

then

$\mathscr{R}(t, \cdot)=[1, \mathfrak{R}(t, 1), \ldots, \mathfrak{R}(t, z)], t \in(-\infty, \infty)$,

where 
$\mathfrak{R}(t, u)=1$ for $t<0, \mathfrak{R}(t, u)=\exp [-t]$ for $t \geq 0, u=1,2, \ldots, z$,

is its limit reliability function.

Motivation: Since for each fixed $u$ we have

$a_{n}(u) t+b_{n}(u)<0$ for $t<0$

and

$a_{n}(u) t+b_{n}(u) \geq 0$ for $t \geq 0$,

then

$R\left(a_{n}(u) t+b_{n}(u), u\right)=1$ for $t<0$

and

$R\left(a_{n}(u) t+b_{n}(u), u\right)=\exp \left[-\lambda(u)\left(a_{n}(u) t+b_{n}(u)\right)\right]$

$$
=\exp [-t / n] \text { for } t \geq 0 .
$$

Hence, considering (3), we get

$\mathfrak{R}(t, u)=\lim _{n \rightarrow \infty} \boldsymbol{R}_{n}\left(a_{n}(u) t+b_{n}(u), u\right)=\lim _{n \rightarrow \infty} 1^{n}=1$ for $t<0$

and

$\mathfrak{R}(t, u)=\lim _{n \rightarrow \infty} \boldsymbol{R}_{n}\left(a_{n}(u) t+b_{n}(u), u\right)=\lim _{n \rightarrow \infty} \exp [-t]=\exp [-t]$ for $t \geq 0$,

which by Definition 5 completes the proof.

\section{Availability of large multi-state systems}

The following two corollaries based on Lemma 1 and Corollary 1 are justified in [6]. 
Corollary 2. If the components of the homogeneous multi-state renewal series system with the ignored time of renewal have exponential reliability functions, then the mean value and the variance of the number of exceeding the critical reliability state $r$ during the time $t, t \geq 0$, are respectively given by

$$
\bar{H}(t, r)=\frac{t}{\mu(r)}, \bar{D}(t, r)=\frac{t}{(\mu(r))^{3}}(\sigma(r))^{2}, t \geq 0, \quad r \in\{1,2, \ldots, z\},
$$

where

$$
\mu(r)=\frac{1}{n \lambda(r)}, \sigma(r)=\frac{1}{n \lambda(r)}, r \in\{1,2, \ldots, z\}
$$

Corollary 3. If the components of the homogeneous multi-state renewal series system with the non-ignored time of renewal have exponential reliability functions and the system renewal time have a distribution function with the mean value $\mu_{0}(r)$ and the variance $\sigma_{0}^{2}(r)$, where $r$ is a system reliability critical state, then:

i) the mean value and the variance of the number of exceeding the critical reliability state $r$ during the time $t, t \geq 0$, are respectively given by

$$
\begin{aligned}
& \overline{\bar{H}}(t, r) \cong \frac{t}{\mu(r)+\mu_{0}(r)}, \overline{\bar{D}}(t, r) \cong \frac{t}{\left(\mu(r)+\mu_{0}(r)\right)^{3}}\left((\sigma(r))^{2}+\left(\sigma_{0}(r)\right)^{2}\right), \\
& r \in\{1,2, \ldots, z\},
\end{aligned}
$$

ii) the availability coefficient at the moment $t, t \geq 0$, is given by

$$
A(t, r) \cong \frac{\mu(r)}{\mu(r)+\mu_{o}(r)}, t \geq 0, r \in\{1,2, \ldots, z\}
$$

where

$$
\mu(r)=\frac{1}{n \lambda(r)}, \sigma(r)=\frac{1}{n \lambda(r)}, r \in\{1,2, \ldots, z\} .
$$




\section{Cost analysis of large multi-state system}

We assume that the operation cost of a single basic component of the considered series multi-state system in the operation time $\theta, \theta \geq 0$, amounts

$c_{i}(\theta), i=1,2, \ldots, n$.

Then, the total cost of the non-failed system during the operation time $\theta$, $\theta \geq 0$, is given by

$$
C(\theta)=\sum_{i=1}^{n} c_{i}(\theta), \theta \geq 0 .
$$

Now, we additionally assume that the system is renewed (repaired) after failure, its renewal time is ignored and the cost of the system singular renovation is $c_{i g}$.

Then, the total operation cost of the renewed system with ignored its renewal time during the operation time $\theta, \theta \geq 0$, amounts

$$
C_{i g}(\theta) \cong \sum_{i=1}^{n} c_{i}(\theta)+c_{i g} \bar{H}(\theta, r), \quad \theta \geq 0,
$$

where $\bar{H}(\theta, r)$ is the mean value of the number of exceeding the critical reliability state $r$ during the time $\theta$, given in Corollary 2 by (7) and (8).

Now, we assume that the system is renewed after failure, its renewal time is not ignored and have distribution function with the mean value and the standard deviation

$$
\mu_{0}(r), \sigma_{0}(r)
$$

and the cost of the system singular renovation is $c_{n i g}$.

Then, the total operation cost of the renewed system with not ignored its renewal time during the operation time $\theta, \theta \geq 0$, amounts

$$
C_{\text {nig }}(\theta) \cong \sum_{i=1}^{n} c_{i}(\theta)+c_{\text {nig }} \overline{\bar{H}}(\theta, r), \theta \geq 0,
$$


where $\overline{\bar{H}}(\theta, r)$ is the mean value of the number of exceeding the critical reliability state $r$ during the time $\theta$, given in Corollary 3 by (9) and (11).

\section{Reliability, availability and cost analysis of large telecommunication network}

We consider a part of a city telecommunication network composed of $n=2500$ telephone subscribers' cables linked by the head of distributive cables. And, we deal with the reliability and availability evaluation of the system composed of telephone subscribers' cables only, further also called a telecommunication system.

\subsection{Reliability of telecommunication network}

We assume that the components of the telecommunication system are fivestate $(\mathrm{z}=4)$ and have exponential reliability functions

$R(t, \cdot)=[1, R(t, 1), R(t, 2), R(t, 3), R(t, 4)], t \in(-\infty, \infty)$,

where

$R(t, u)=1$ for $t<0, R(t, u)=\exp [-\lambda(u) t]$ for $t \geq 0, \lambda(u)>0, u=1,2,3,4$,

with the rates of departure from the reliability state subsets $\{u, u+1, \ldots, z\}$ given by

$\lambda(u)=\frac{1}{60-10 u}, u=1,2,3,4$.

Assuming that the telecommunication system is in the reliability state subset $\{u, u+1, \ldots, z\}$ if all its components are in this reliability state subset, we conclude that the system is a homogeneous five-state series system and according to (1)-(2), its reliability function is given by the vector

$\boldsymbol{R}_{n}(t, \cdot)=\left[1, \boldsymbol{R}_{n}(t, 1), \boldsymbol{R}_{n}(t, 2), \boldsymbol{R}_{n}(t, 3), \boldsymbol{R}_{n}(t, 4)\right]$ for $t \geq 0$, 
where

$\boldsymbol{R}_{n}(t, 1)=\exp \left[-\frac{250}{5} t\right]$ for $t \geq 0$,

$\boldsymbol{R}_{n}(t, 2)=\exp \left[-\frac{250}{4} t\right]$ for $t \geq 0$,

$\boldsymbol{R}_{n}(t, 3)=\exp \left[-\frac{250}{3} t\right]$ for $t \geq 0$,

$\boldsymbol{R}_{n}(t, 4)=\exp \left[-\frac{250}{2} t\right]$ for $t \geq 0$.

Corollary 4. If a critical reliability state of the telecommunication system is $r=3$, then the mean value and the standard deviation of the system lifetime up to exceeding this critical state respectively are:

$\mu(3)=\frac{3}{250}, \sigma(3)=\frac{3}{250}$.

\subsection{Availability of large telecommunication network}

Application of Corollary 4, Corollary 2 and Corollary 3 yields the following two results.

Corollary 5. If the telecommunication system is renewal, its critical reliability state is $r=3$, its renewal time is ignored, then the mean value and the variance of the number of exceeding the critical reliability state during the time $t, t \geq 0$, are respectively given by

$$
\bar{H}(t, 3)=\frac{250 t}{3}, \bar{D}(t, 3)=\frac{250 t}{3}, t \geq 0 .
$$


Corollary 6. If the telecommunication system is renewal, its critical reliability state is $r=3$, its renewal time is not ignored and have a distribution function with the mean value and the standard deviation respectively given by

$\mu_{0}(3)=0.003, \sigma_{0}(3)=0.003$,

then the mean value, the variance of the number of exceeding the critical reliability state and the availability coefficient during the time $t, t \geq 0$, are respectively given by

$$
\begin{aligned}
& \overline{\bar{H}}(t, 3) \cong \frac{t}{0.012+0.003}=\frac{t}{0.015}, \overline{\bar{D}}(t, 3) \cong \frac{t}{0.022}, t \geq 0, \\
& A(t, 3) \cong \frac{0.012}{0.012+0.003}=0.8, t \geq 0 .
\end{aligned}
$$

\subsection{Cost analysis of reliability and availability of large telecommunication network}

We assume that the operation cost of a single basic component of the considered series multi-state system in the operation time $\theta, \theta \geq 0$, amounts

$c_{i}(\theta)=20 \$, i=1,2, \ldots, n$.

Then, the total cost of the non-failed system during the operation time $\theta$, $\theta \geq 0$, according to (12), is given by

$C(\theta)=50.000 \$, \theta \geq 0$.

Now, we additionally assume that the system is renewed (repaired) after failure, its renewal time is ignored and the cost of the system singular renovation is $c_{i g}=250 \$$.

Then, the total operation cost of the renewed system with ignored its renewal time during the operation time $\theta, \theta \geq 0$, according to (13) and (16), amounts 


$$
C_{i g}(\theta)=50.000+\frac{62.500 \theta}{3} \$, \theta \geq 0 .
$$

Now, we assume that the system is renewed after failure, its renewal time is not ignored and have distribution function with the mean value and the standard deviation

$\mu_{0}(r)=0.003, \sigma_{0}(r)=0.003$,

and the cost of the system singular renovation is $c_{n i g}=250 \$$.

Then, the total operation cost of the renewed system with not ignored its renewal time during the operation time $\theta, \theta \geq 0$, according to (24) and (27), amounts

$$
C_{n i g}(\theta) \cong 50.000+\frac{250 \theta}{0.015}, \theta \geq 0 \text {. }
$$

\section{Conclusions}

In the paper the asymptotic approach to the reliability and availability evaluation of multi-state series systems have been considered. Theoretical results presented have been illustrated by an example of their application in reliability and availability evaluation and cost analysis of a large telecommunication system. These evaluations, despite not being precise may be a very useful, simple and quick tool in approximate reliability and availability evaluation and cost analysis and optimisation, especially during the design of large multi-state systems, and when planning and improving their safety and effectiveness operation processes. Optimisation of the reliability structures of large multi-state systems with respect to their operation processes safety and costs is complicated and often not possible to perform by practitioners because of the mathematical complexity of the exact methods. The proposed method offers enough simplified formulae to allow significant simplifying of reliability and availability optimising calculations.

The results presented in the paper suggest that it seems reasonable to continue the investigations focusing on:

- methods of improving reliability and availability for large multi-state systems with different structures, 
- methods of reliability and availability optimisation for large multi-state systems related to costs and safety of the system operation processes.

\section{References}

1. Aven T. On performance measures for multi-state monotone systems. Reliability Engineering and System Safety 41, 259-266, 1993.

2. Barlow R., Wu A. Coherent systems with multi-state components. Mathematics of Operations Research 4, 275-281, 1978.

3. Kolowrocki K. (2004). Reliability of Large Systems. Elsevier, 2004.

4. Lisnianski A., Levitin G. Multi-state System Reliability. Assessment, Optimisation and Applications. World Scientific Publishing Co., 2003.

5. Xue J. On multi-state system analysis. IEEE Transactions on Reliability 34, 329-337, 1985.

6. Kolowrocki K., Kwiatuszewska-Sarnecka B. Asymptotic approach to reliability improvement of multi-state renewal systems, Chapter 25 in Asymptotic Approach to Reliability Analysis and Optimization of Complex Transportation Systems, Research Project Report, Maritime University, Gdynia, 2005, 1935-2081, 2005.

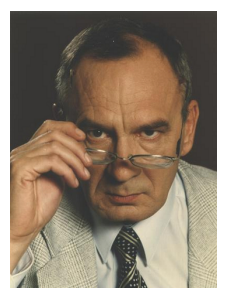

Krzysztof Kolowrocki is a Professor and the Head of Mathematics Department at the Faculty of Navigation of Gdynia Maritime University. His field of interest is mathematical modeling of safety and reliability of complex systems and processes. He has published over 200 scientific works. He is the Chairman of Polish Safety and Reliability Association. His home site can be found at: http://www.am.gdynia.pl/ katmatkk/

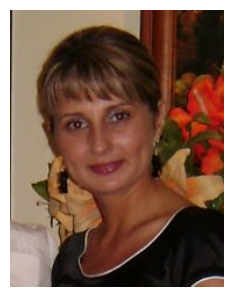

Joanna Soszynska is an Assistant Professor in Department of Mathematics at the Faculty of Navigation of Gdynia Maritime University. Her field of interest is mathematical modeling of safety and reliability in complex systems in variable operation conditions. She has published over 20 papers in scientific journals and conference proceedings. 
